\title{
Total thoracic aorta reconstruction against graft infection in a patient with chronic empyema developed after lung cancer surgery
}

\author{
Jun Yokote, MD, Akihiko Usui, MD, Hideki Oshima, MD, Noriyasu Usami, MD, Kohei Yokoi, MD, and \\ Yuichi Ueda, MD, Nagoya, Japan
}

Prosthetic graft infection is rare; however, it is lethal in up to $90 \%$ of cases in which it does occur, especially in the thoracic aorta. ${ }^{1}$ Major concerns of treatment for this complication are infection control, resection of the infected graft, reconstruction of the vessels, and prevention of reinfection. $^{2,3}$ If feasible, total aortic reconstruction without cardiopulmonary bypass is ideal for surgical treatment, especially during the active phase of infection. We report total thoracic aorta reconstruction against graft infection

From the Department of Cardio-Thoracic Surgery, Nagoya University Graduate School of Medicine, Nagoya, Japan.

Received for publication May 14, 2008; accepted for publication July 15, 2008; available ahead of print Sept 9, 2008.

Address for reprints: Jun Yokote, MD, Department of Cardio-Thoracic Surgery,

Nagoya University Graduate School of Medicine, 65 Tsurumai-cho, Showa-ku,

Nagoya 466-8550, Japan (E-mail: j-yokote@wf6.so-net.ne.jp).

J Thorac Cardiovasc Surg 2009;138:779-81

$0022-5223 / \$ 36.00$

Copyright (c) 2009 by The American Association for Thoracic Surgery

doi:10.1016/j.jtcvs.2008.07.026
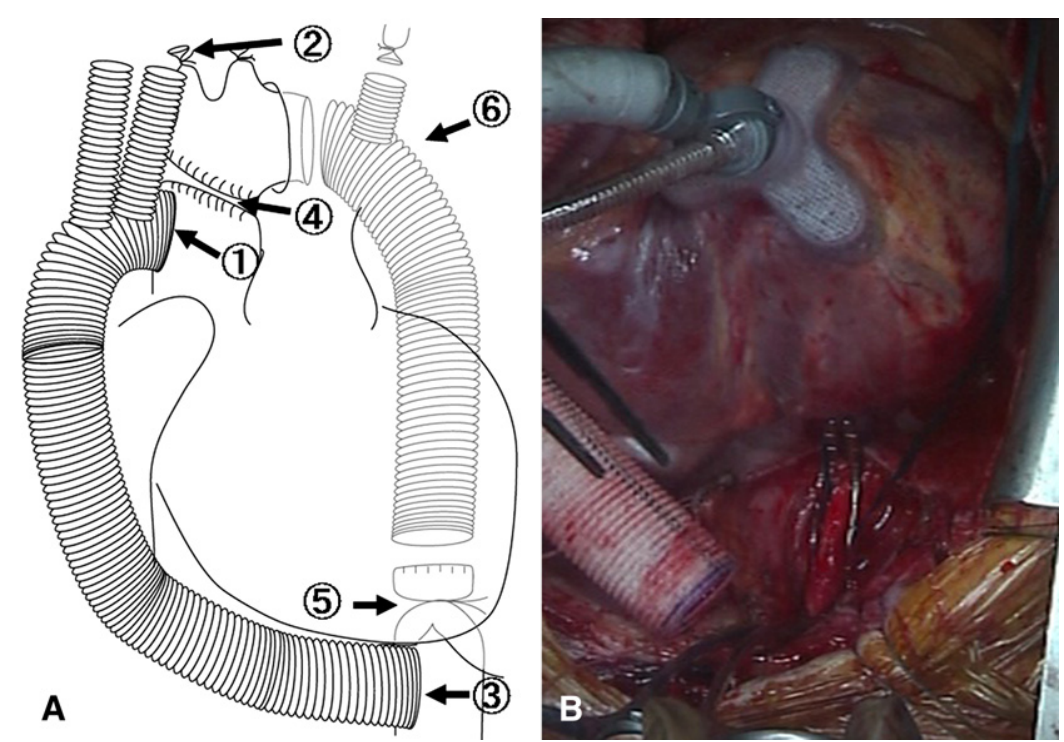

FIGURE 1. A, Operative scheme. First, a neoarch graft was anastomosed to the ascending aorta (arrow 1). Next, a neoarch was anastomosed to the left carotid artery and brachiocephalic artery (arrow 2). Then, an anastomosis between the graft and the distal descending aorta was achieved via the posterior pericardium (arrow 3). Finally, the proximal aortic arch was transected (arrow 4) and the descending aorta was ligated (arrow 5 ). Two days later the infected graft was removed by left thoracotomy (arrow 6). B, Exposure of the descending aorta though the posterior pericardium. There is enough space for partial clamping of the descending aorta and constructing an anastomosis between the graft and the descending aorta. 


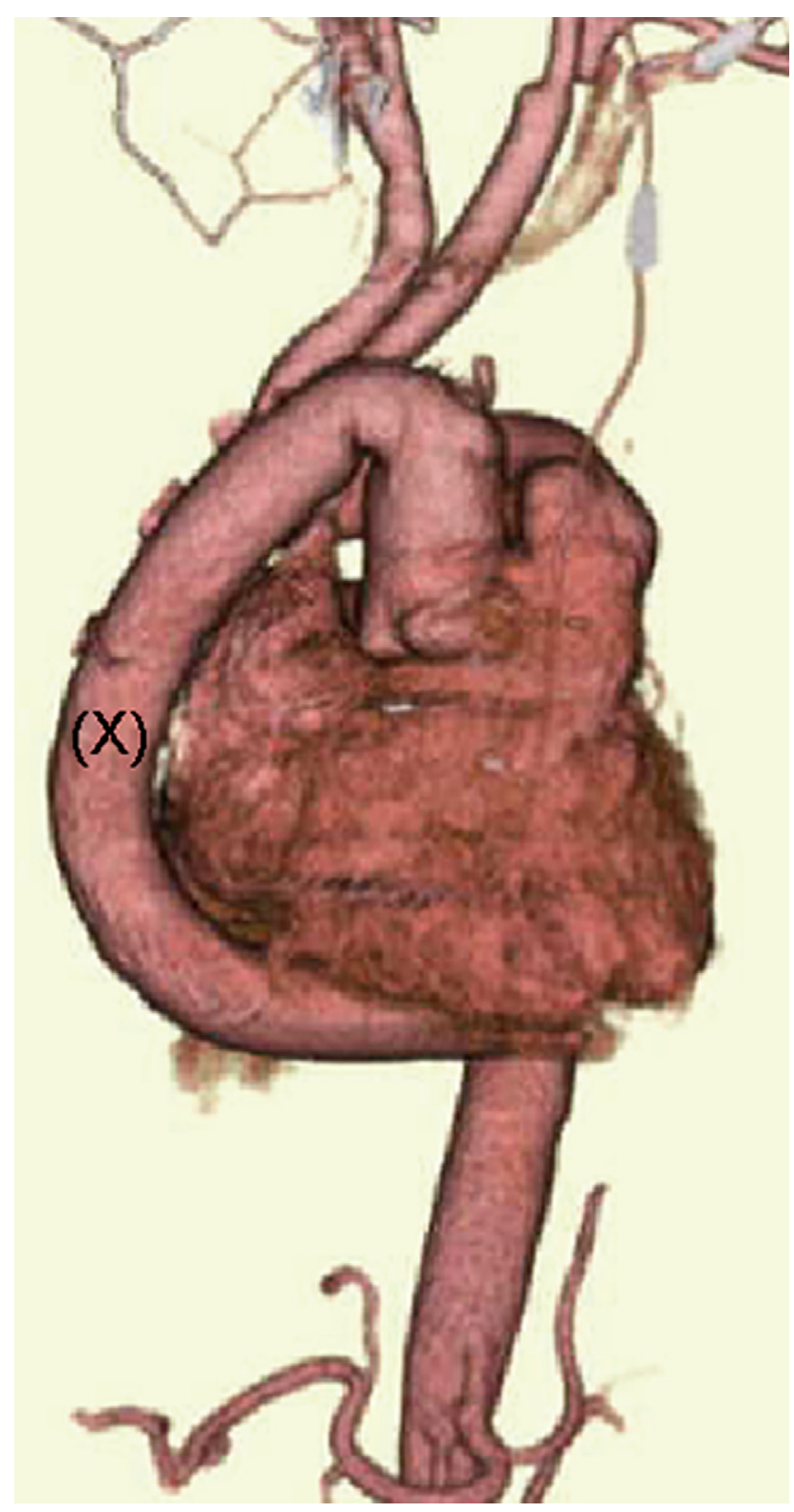

FIGURE 2. Postoperative 3-dimensional computed tomography. The graft $(X)$ passes to the right side of the heart, and there is no evidence of compression of the heart.

fibrotic omentum. We planned a total thoracic aorta reconstruction with a neoarch through a median sternotomy without cardiopulmonary bypass. First, an anastomosis between the ascending aorta and a 2-branched neoarch graft was constructed in an end-to-side fashion with a side-bite occluding clamp (Figure 1, $A$, arrow 1). Next, individual anastmoses to the left common carotid artery and the brachiocephalic trunk in an end-to-end fashion were performed (Figure 1, $A$, arrow
2). Then, verticalization of the heart was established by using a heart positioner, and the posterior pericardium was opened (Figure 1, B). An anastomosis between the graft and the distal descending aorta was achieved (Figure 1, A, arrow 3). Finally, the proximal aortic arch was transected using an Endo GIA (Autosuture, Mansfield, Mass) and reinforced with an additional running suture, and the descending aorta was ligated at the proximal site of the anastomosis (Figure 1, A, arrow 4 and 5). Two days later, the infected graft was removed through the left thoracotomy (Figure 1, $A$, arrow 6). Postoperative 3-dimensional CT indicated that the blood flow would be enough to supply the lower body (Figure 2). Eight months after the surgery, closure of the bronchial fistula and thoracic space with a left rectus abdominis free musculocutaneous flap and a left thoracoplasty were performed. After the operation, onelung mechanical ventilation obstruction of the left main bronchus with bronchial blocker was used to maintain the stability of the free flap for 10 days. The infection was well controlled and no aortic events were noted for over 2 years.

\section{DISCUSSION}

The present case was complicated by chronic recurrent empyema with bronchial fistula developed after advanced lung cancer surgery, which required open window thoracotomy and then removal of the infected graft with establishment of a new circulation. Because in this condition in situ reconstruction was unsuitable to prevent reinfection, we chose an extra-anatomic bypass from the ascending aorta to the descending aorta via the pericardial cavity, which was not affected by the infection. Because a cardiopulmonary bypass might reduce immunologic competence and enhance infection, ${ }^{5}$ we decided against cardiopulmonary bypass to control the infection. Aortic arch reconstruction without a cardiopulmonary bypass can be performed; however, it involves certain risks and disadvantages. Brief interruption of the neck vessels may cause ischemic changes and embolic events in the brain. Moreover, massive bleeding may occur when transecting the ascending aorta while applying the occluding clamp. To prevent bleeding, we used the Endo GIA first and confirmed closure of the stump with additional sutures. In the present case, resection of the infected graft was performed 2 days after aortic reconstruction. Simultaneous operation with different surgical fields increases surgical damage and the risk of remote infection, which might cause mediastinitis. We therefore planned a staged operation.

In summary, we present the successful surgical treatment of an infected thoracic aortic graft after a left pneumonectomy for lung cancer involving the aortic 
arch and the left subclavian artery and distal arch replacement. We reconstructed the total thoracic aortic system by using an extra-anatomic bypass via the pericardial cavity without a cardiopulmonary bypass, and controlled the infection. We believe that this is a useful strategy for the treatment of distal aortic arch graft infections.

\section{References}

1. Darouiche RO. Treatment of infections associated with surgical implants. $N$ Engl J Med. 2004;350:1422-9.
2. Perera GB, Fujitani RM, Kubaska SM. Aortic graft infection: update on management and treatment options. Vasc Endovascular Surg. 2006;40:1-10.

3. Hart JP, Eginton MT, Brown KR, Seabrook GR, Lewis BD, Edmiston CE Jr, et al. Operative strategies in aortic graft infections: is complete graft excision always necessary? Ann Vasc Surg. 2005;19:154-60.

4. Sai N, Maeda M, Miyahara K, Sakurai H, Nakayama M, Takemura H. A case of primary squamous cell lung cancer invading the wall of the distal aortic arch and the left subclavian artery: successful surgical management using ECC selective cerebral perfusion. Nippon Geka Gakkai Zasshi. 1998;99:264-7 [in Japanese]

5. Kazuyoshi T, Fumio $\mathrm{Y}$, Kohei K, Izumi N, Hiroshi S, Toshio A, Yasunaru K. Cardiopulmonary bypass and cellular immunity: changes in lymphocyte subsets and natural killer cell activity. Ann Thorac Surg. 1993;55: 625-30.

\title{
Single-stage repair of aortopulmonary window with interrupted aortic arch by transection of the aorta and direct reconstruction
}

\author{
Masahiro Yoshida, MD, ${ }^{\mathrm{a}}$ Masahiro Yamaguchi, $\mathrm{MD}, \mathrm{PhD},{ }^{\mathrm{b}}$ Yoshihiro Oshima, MD, PhD, ${ }^{\mathrm{a}}$ \\ Shigeteru Oka, MD, PhD, ${ }^{\mathrm{a}}$ Tomonori Higuma, MD, ${ }^{\mathrm{a}}$ and Yutaka Okita, MD, PhD, ${ }^{\mathrm{c}}$ Kobe and Akashi, Japan
}

Aortopulmonary window (APW) associated with interrupted aortic arch (IAA) is a rare congenital heart defect that requires early surgical treatment to avoid the progression of pulmonary hypertension. ${ }^{1}$ Single-stage repair is currently the preferred approach because of its potential to provide normal systemic and pulmonary circulations. ${ }^{2,3}$ We report a new technique of single-stage repair for this complex entity by transection of the aorta and direct reconstruction of both aorta and pulmonary artery.

\section{TECHNIQUE}

The operation is performed through a median sternotomy. Cardiopulmonary bypass is established by brachiocephalic arterial and bicaval cannulations. The aortic arch and the descending aorta are dissected completely. After clamping of the proximal arch, the left carotid artery, the left subclavian artery, and the descending aorta, the lesser curva-

\footnotetext{
From the Department of Cardiovascular Surgery, ${ }^{a}$ Kobe Children's Hospital, Kobe, Japan; the Department of Cardiovascular Surgery, ${ }^{\mathrm{b}}$ Akashi Medical Center, Akashi, Japan; and the Division of Cardiovascular, Thoracic, and Pediatric Surgery, ${ }^{\mathrm{c}}$ Kobe University Hospital, Kobe, Japan.

Received for publication April 10, 2008; accepted for publication July 6, 2008; available ahead of print Sept 25, 2008.

Address for reprints: Masahiro Yoshida, MD, Department of Cardiothoracic Surgery, Kobe Children's Hospital, 1-1-1 Takakuradai Suma-ku, Kobe, 654-0081, Japan (E-mail: masahiro.yoshida@chp.edu).

J Thorac Cardiovasc Surg 2009;138:781-3

$0022-5223 / \$ 36.00$

Copyright $(C) 2009$ by The American Association for Thoracic Surgery

doi:10.1016/j.jtcvs.2008.07.031
}

ture of the aortic arch is opened. Ductal tissue is removed completely after transection of the descending aorta. The aortic arch reconstruction is completed with side-to-end anastomosis between the arch and the descending aorta (Figure 1, A). After crossclamping of the aorta, the blood cardioplegia is infused, and the ascending aorta is divided from the connecting pulmonary artery along the specially designed division line, as shown in Figure $1, B$. The main and right pulmonary arteries are repaired by direct suture, and the ascending aorta is also reconstructed directly (Figure 1,C).

\section{CLINICAL SUMMARIES}

Since Yamaguchi, the former director of cardiovascular surgery in Kobe Children's Hospital, performed the first case in 2002, a total of 3 consecutive patients with a diagnosis of APW with IAA have undergone single-stage repair with this technique at the ages of 5 months, 2 months, and 5 days. According to the Cerolia and Patton classification for $\mathrm{IAA}^{4}$ and the Richardson classification for $\mathrm{APW},{ }^{5}$ all cases were type A of IAA and types I and II of APW, which means that the defect was very large from just above the sinus of Valsalva to the right pulmonary artery. In all cases, single-stage repair was performed successfully by direct reconstruction of the aorta and pulmonary artery with our technique. In the most recent case, in addition to brachiocephalic arterial and bicaval cannulations, blood circulation to the lower half body was maintained by descending aortic cannulation. The cardiopulmonary bypass and crossclamping times were $165 \pm 26$ and $58 \pm 21$ minutes, respectively. 